\title{
Regulatory function of macroscopic quantum states of electrons in cell metabolism
}

The article reviews macroscopic quantum mechanisms of the effect of ion-radical oxygen species included in complexes with associated water phase on cell metabolism, and shows that processes triggering metabolic regulation are associated with keto-enol tautomerism of protein polypeptide chains regulated by amplitude-phase states of a collective electron wave packet in associated water composition.

\section{Keywords: macroscopic quantum states, wave packet of electrons, keto-enol tautomerism, cell metabolism}

\section{Acronyms}

Valeokinesis: Constant work of protective adaptive mechanisms at all levels of organization: metabolic, subcellular, cellular, organ, systemic, organismic; Coherence: Coherent progress of a number of oscillating or wave processes in time; Tunnelling: Capability of a particle to pass through a potential barrier of any shape and height; Phonon: a quasiparticle representing a quantum of crystal atom oscillation; Tautomerism: a special type of isomerism specific for many organic compounds existing as a mixture of two or more isomers (tautomeric forms) that interconvert; mtDNA: mitochondrial DNA; Mitoptosis: programmed death of the mitochondria

Currently, there is an open question in biophysics of the cell and of the living substance as a whole, a question important for methodologically substantiated approach to researching the favorable hygienic and environmental conditions for human valeokinesis: what is the trigger mechanism of cell metabolism and how is this function implemented in a living substance?

It has been recognized, that a key link of cell metabolism maintaining the human body in thermodynamically unbalanced condition is determined by the inflow of negative entropy from the environment [1-3].

Such a role of "negative entropy provider" [4] has been claimed by high-energy "nutrition" phosphates, for instance, adenosine triphosphate (ATP) synthesized in mitochondria, the power plant of the cell. But in the recent years, research found such a source of "negative entropy" in the environmental electrons. Cell metabolism trigger mechanism function, as well as regulatory functions performed by nonspecific body regulation system, is attributed to electrons contained in the associated water phase in the delocalized quantum state [5,6]. In lieu of this, it makes sense to review the sources of electron inflow from the environment and their role in cell metabolism from a scientific perspective of macroscopic quantum effects.

Scientific basis for non-contact and non-local interaction implemented by electron transfer is found in the idea of macroscopic quantum states [7-10] with properties of spatial and temporal coherence. Basic assumptions of the ideas of coherence and macroscopic quantum state are based upon the analysis of collective behavior of electrons, which can be described on the basis of the de Broglie's concept of wave interference [11]. De Broglie wave and magnetic vector potential contained in the De Broglie wave equation are, basically, the "electromotive force" (distinct from electric field). Similar force acts on the charged objects. Such objects in the environment are, according [12,13] to electron Bose condensate (with wave function amplitude not equal to zero), electrons weakly bound with atoms and electrons contained in ion-radicals in condensed media.
Anatoly Stekhin ${ }^{1}$, Galina Yakovleva ${ }^{1}$, Konstantin Pronko ${ }^{2}$ \& Vladimir Zemskov ${ }^{* 2}$

${ }^{1}$ Center for Strategic Planning and Control of Medical and Biological Risks to Health, Moscow, Russia

${ }^{2}$ Department of Research and Development at Facecontrol, Inc., Florida, Miami, USA

*Author for correspondence:

vzemskov@facecontrol.biz 
De Broglie waves describe delocalized state of electrons. For example, electrons of atoms in $s, \mathrm{p}, \mathrm{d}$ and $\mathrm{f}$ states occupy larger volume as the force binding them with atomic nucleus decreases. In reference to reactive oxygen species (ROS), this means that delocalization degree of charge-uncompensated electrons in ion-radicals with weak bond is maximal in comparison with $\mathrm{OH}^{-(*)}$ and other anions in biological environment. Taking into account the interference of wave functions of single electrons in ion-crystalline associate [3], delocalized states of electrons acquire macroscopic nature comparable with the size of cells.

Based on concepts of macroscopic quantum interaction, electrons enter organisms not only as negatively charged ions from the air with anion radical forms of oxygen and with some organic compounds contained in food and water (in ionic form), but, also by a non-contact way, through macroscopic quantum tunneling $[14,15]$. Such an approach radically changes the existing ideas of valeogenic factors of organisms and signals the necessity to study electronic activity of the environment as a major vital factor.

\section{Mechanism of electron transfer in aqueous media}

Basic physical and chemical processes in water, which result in emergence of macroscopic quantum effects and change of its electro physical properties, are currently connected with instabilities of associated water phase [3]. As the phase instabilities occur, physical conditions are implemented reflecting the processes of non-contact transfer of electrons, which can be represented as a simplified diagram (FIGURE 1).

Quantum condensation of electrons, occurring as a result of excitation of coherent phase of associated water during development of phase instability, proceeds in two stages: 1-" release" of a whirl accompanied by excitation of macroscopic quantum state and 2 condensation of additional electrons from the environment by the whirl [3]

$$
\begin{aligned}
& 1^{\text {st }} \text { stage }-4 \Sigma \mathrm{OH}^{-(*)} \rightarrow 4 \Sigma \mathrm{OH}^{*}+\Sigma 2 \mathrm{e}^{-} \\
& 2^{\text {nd }} \text { stage }-\Sigma 2 \mathrm{e}^{-} \rightarrow \Sigma \Sigma 2 \mathrm{e}^{-}
\end{aligned}
$$

The second stage (of quantum condensation) from the perspective of classical electrodynamics may be associated with non-stationary dynamics of "initiating" electromagnetic whirl characterized by phonon deficiency, which results in decreased temperature of the phase state along with phase transfers in the whirl itself $[16,17]$. From quantum perspective, electron transfer occurs due to non-local effect of the magnetic vector potential formed by non-stationary dynamics of collective electron packet released from the bound state as a result of developing phase instability.

Hence, quantum condensation of electrons proceeding with formation of molecular hydrogen and short-period superoxide ionradical, serves as a source of ion-molecular forms of chemical compounds in the living body. Enzymes containing metals with variable valence perform "modulation" functions of associated water state, stimulating its phase instabilities, which is accompanied with recondensation of electrons: at phase growth stage, concentration of electrons in ion-metallic associates increases, and at instability (degradation) stage, electrons recondensate on quantum-conjugated centers in the environment, and free radicals are formed.

In this regard, primary electron receptors in the body and a system of non-specific cell metabolism regulation are associated with formation and degradation of collectivized states of ion-molecular forms of ROS. In turn, biological activity and functional orientation of cell metabolism (of the body) depend directly on primary electron receptors activity.

\section{Primary electron receptors in the body}

As shown above, when evaluating the biological role (specifically, regulating function) of ROS, it is necessary to consider the noncontact and non-local nature of donoracceptor chain interaction. Such interaction is a determining factor at all organization levels of a living substance, including its foundational base - individual cells and subcellular structures.

A number of studies have established the fact that cell activity factors are formed outside the cells and are connected with ion-radical forms of oxygen [18-23]. From the perspectives of morphology and cell specialization, the role of primary macroscopic acceptor of electrons can be performed by energetic adapted structure. Additionally, the external membrane serves as 


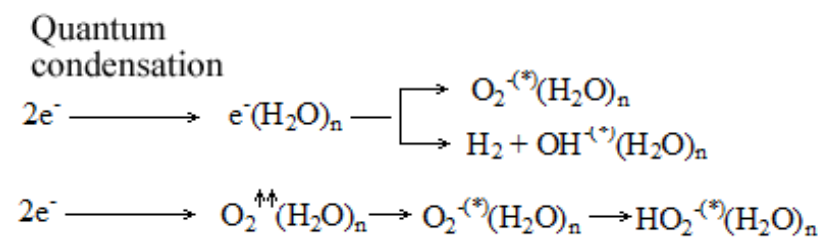

Environment

Ion-radical forms of ROS

$$
\begin{gathered}
\text { Decay of ion-molecular forms of ROS } \\
2\left[\mathrm{O}_{2}^{-(*)}\left(\mathrm{H}_{2} \mathrm{O}\right)_{\mathrm{n}} \ldots \mathrm{OH}^{-(*)}\left(\mathrm{H}_{2} \mathrm{O}\right)_{\mathrm{n}}\right] \rightarrow 2 \mathrm{O}_{2}^{*+4}+4 \mathrm{n}\left(\mathrm{H}_{2} \mathrm{O}\right)+2 \mathrm{OH}^{*}+2 \mathrm{e}^{-} \\
2\left[\mathrm{HO}_{2}^{-(*)}\left(\mathrm{H}_{2} \mathrm{O}\right)_{\mathrm{n}} \ldots \mathrm{OH}^{-(*)}\left(\mathrm{H}_{2} \mathrm{O}\right)_{\mathrm{n}}\right] \longrightarrow 2 \mathrm{HO}_{2}^{*}+4 \mathrm{n}\left(\mathrm{H}_{2} \mathrm{O}\right)+2 \mathrm{OH}^{*}+2 \mathrm{e}^{-}
\end{gathered}
$$

FIGURE 1. Quantum condensation of electrons, occurring as a result of excitation of coherent phase of associated water during development of phase instability, proceeds in two stages

the main point of localization of cell activity regulators. Degree of activity (concentration) of ion-radicals on the external surface of the membrane depends on the catalytic activity of intramembrane and intracellular enzymes. For example, maximum electron activity (on the external surface of the membrane) of subcellular mitochondria is determined by concentration of hemin iron in the mitochondria, and in warmblooded organisms, this function is mainly specialized in erythrocytes also containing high concentration of hemin iron $[1,24]$.

Specialized cells are adapted to interacting with electrons contained in ion-molecular forms of oxygen entering the body with air, water, electromagnetic radiation and directly from the environment. For example, anions entering pulmonary tissue of animal body with air do not ingress the blood stream but degrade in the alveoli with recondensation of released electrons on external membranes of blood erythrocytes. Similar processes of electron accumulation from water occur in the gastrointestinal tract of the body following water and food intake. Basic processes of electron transport from the environment to the body, irrespective of the ways of entry (aeroions, water and food, environment), are of macroscopic quantum nature complying with objective laws of superfluid transfer of electrons [25,26], which forms a non-local bond between primary electron receptors and energy (electron) state of environmental structures.

Therefore, cell activity comes to be dependent on both the electron state of the external cell membrane, determined by the concentration of ion-radical ROS forms, as well as the electrophysical state of the environment.

\section{Quantum mechanisms of cell me- tabolism regulation}

Mechanisms of cell metabolism regulation recognized in current biophysical science are commonly based on concepts of chemical interactions, where the regulatory role is postulated by "fine mechanisms of enzymatic catalysis", which affect the orientation of cell reaction. With this in view, statements of some authors that "ROSs are universal regulatory agents, factors favorably affecting processes of vital activity from the cell level to the level of the whole body" [26] become weakly substantiated, as it is hard to expect "fine mechanisms of interaction" from purely chemical interaction of the simplest chemical compounds. Even the fact that generation of ion-radicals and other ROSs by cells precedes other events in the intracellular information chain [27] is not a proof of purely chemical mechanism of cell function regulation. Obviously, answers to questions regarding regulatory function of ROSs shall be found at a higher level of water medium organization, namely, in coherent states of water where ROSs is active participants of processes.

Let us review the role of ROSs using an example of keto-enol tautomerism of proteins performing one of the main functions in cell cycles. It is well known that keto-enol tautomerism is closely connected with conformational states of proteins, which are basic conditions of living substance. Both these processes are inter-dependent and extremely sensitive to the electrons surrounding the proteins $[15,28]$. 
Note that conformational states of proteins are regulated by the associated phase of water stabilized by electrons. In particular, the strength of hydrogen bonds between COand $\mathrm{NH}$ - groups of polypeptide backbone in $\alpha$-spiral structure primarily depends on the electron density on carbonyl atom of oxygen or far-ranging inductive effect of other charges in the structure of associated phase of water [15]. The association-induction theories proposed by Gilbert Ling, serving as an explanation to mechanisms of conformational changes of proteins and function of ion pumps in the cell, associates these processes with formation and degradation of associated phase of water.

In accordance with concepts of Ling's association-induction theory and our concepts of ion-crystalline association of water [1], conformational states of proteins and keto-enol isomerization are determined by mechanisms of inductive effect of distributed electric charges (of ion-radicals of ROSs) in coherent phase of water. These experimentally discovered propositions can be taken as a basis of electron mechanisms of remote control of protein condition in living organisms. According to Ling [15], "dynamic balance between keto-form of peptide bond and enol bond $(-\mathrm{C}=\mathrm{O}-\mathrm{NH} \leftrightarrow$ $\mathrm{COH}=\mathrm{N}-$ ) forms a unique resonance structure. Due to tautomerism, peptide bond partially (by $40 \%$ ) has a nature of double (conjugated) bond, which manifests as a decrease in its length $(1,32 \AA)$ in comparison with the length of single -C-N- bond (1,47 ̊). This 'vibration' makes long polypeptide chain highly polarized and, hence, gives it an ability to transmit inductive effect across long distances." In accordance with our point of view, it should be added that distributed electrons in the bound phase of water, forming macroscopic quantum structure, have a regulating effect on keto-enol tautomerism and implement conditions of 'periodic launching' of this process [3]. Experimental data [29-31] on observation of oscillating modes of water self-organization processes, generation of free radicals and electromagnetic emission in physiological media in the presence of ROSs are consistent with such interpretation of metabolism regulating processes.

Ideas about the regulating effect delocalized electric charges of ion-radicals have in the associated phase of water, forming a coherent quantum structure, form a basis for secondary biochemical mechanisms of cell metabolism analysis.

\section{Regulatory role of ROSs}

Pursuant to the above analysis, while ROSs are seen as providers of reaction-capable free radicals participating in the processes of destruction of organic compounds in reality, they are, to even a greater degree, macroscopic regulators of cell metabolism.

At present time, cell metabolism is understood to imply "all reactions, resulting in formation of cell and tissue structural elements, as well as in processes, where energy is obtained from substances contained in cells' [32]. Here, the term 'reaction' denotes a chemical interaction, although conformational processes, processes of keto-enol tautomerism and even more so, processes of macroscopic selforganization of cell structures, electrophysical processes, including their oscillating states, cannot be defined by this term.

Chemical interaction itself does not posit a great interest in the analysis of regulatory role of ROSs, as chemical cycles (of tricarboxylic acids, proceeding with formation of nicotinamide adenine dinucleotide (NADH); of oxidizing phosphorylation aimed to synthesize ATP main energy carrier of the cell; of apoptosis - programmed death of cell and others) are aimed to utilize chemical energy and chemical destruction of products of cell metabolism. Although these processes are also quantum in nature [33], they can hardly be attributed to macroscopic processes due to space limitation, fixed state of active fragments and sufficiently high electron-binding energy in active anion centers of electron conjugation chain [34].

At present time, it is considered that almost the only source of energy used by the cell for its functioning is the energy contained in the adenosine triphosphate (ATP) structure. Production of ATP by the cell performed in the electron-active cell structure, mitochondria, is based on transformation of chemical energy. A common understanding is that ROSs are produced in mitochondria as a result of disorders in normal electron conjugation [35] and are subject to neutralization by enzymes - catalase, superoxide dismutase, peroxidase as by-products of metabolism [36]. 
However, in the recent time, it is proven that ROSs are vital for normal cell metabolism and functioning of the whole body [37-39]. Increase in ROS concentration precedes passing of some stages of ontogenesis (maturation, ageing, apoptosis) [34,40-43]. Meanwhile, usually, activation of antioxidant systems of mitochondria preventing excessive generation of ROSs by respiratory chain and damage of membranes, proteins and other structures of organelles is observed $[40,42,44]$. Absolute values of functional concentrations of hydrogen peroxide reach significant values in the order of $1 \mathrm{mM}$ [45].

According to [46,47], ROSs play a key role in intracellular compensatory mechanisms. For example, in cell respiration disorders (e.g. because of change from glucose nutrition to galactose nutrition) in mitochondria, ATP production in the cell becomes insufficient, which is accompanied by increased production of reactive oxygen species that stimulate an increase in the number of mtDNA copies and, as a consequence, concentration of respiratory chain enzymes. Therefore, along with "clearing" functions (including mitoptosis), ROSs in mitochondria reveal regulatory functions as well, such as activation of uncoupling proteins regulating ATP production and transmission of growth signals through tyrosine kinase. Results found in quoted works reveal an additional role of ROSs: compensatory regulation of cell respiratory chain activity performed through replication activation of mitochondrial DNA. In a sense, regulatory role of ROSs discredits the efficiency of antioxidants for treatment of some diseases, as their use can be harmful since it will block the adaptive compensatory role of ROSs.

Work [36] shows that superoxide-ionradicals produced on the external side of cell membrane regulate intracellular metabolism by changing the relation between recovered and oxidized glutathione and by regulating intracellular biochemical reactions [48]. Similar regulating role is performed by active ionradicals produced in other systems [49], such as xanthine/xanthine oxidase, which interact with thiolic systems of the cell [50]. In turn, a number of enzyme systems in the body regulate the level of ROSs in the cell [51] via neutralization of free radicals and stabilization of ion-radicals.

According to data in works [52,53], such macroscopic processes as apoptosis ('cell disassembly') and mitosis (cell division) are controlled by ion-radicals, too. Orientation of the process (apoptosis or mitosis) is determined by the level of ROSs content [54], which indirectly indicates the determinant role of their quantum states. The latter determine the orientation of electron transport process, the 'driving force' of regulatory effect on the target cell. In this regard, an effect similar to T-lymphocyte is observed, when they activate ('initiation' of apoptosis) from a received charge from a superoxide ion-radical [55]. However, intracellular ion-radicals are capable to induce cell apoptosis, too $[56,57]$, which points to the independence of their effect from the type of charge carrier. We consider that the main condition in order for such processes to take place is the coincidence between parameters of macroscopic donor of electrons wave packets (contained in the form of ion-radicals) and of the acceptor - cell entering the apoptosis state.

Works [58-60] describe macroscopic effects of cell growth stimulation by charges transferred by ion-radicals, initiation of these processes, including activation of energy chains of tyrosine phosphorylation in proteins $[3,61$ 64], expression of growth factors [65], cell differentiation $[66,67]$ and, in turn, proliferation and inhibition of their growth [67-70].

Ion-radicals, as electron carriers, participate in the regulation of calcium-dependent systems of the cell [65], activation of telomerase [71], protein kinase B and C [21,72], and phosphorylation of H3-histon [73]. Works $[73,74]$ denote their role in intracellular redistribution of charge [74].

Many works contain assumptions that hydrogen peroxide in physiological (micromole) concentrations, where it is completely in the ion-molecular form, has a stimulating effect on cells. Activation of gene transcription, cell differentiation and cell cycle take place in the intra-cellular environment containing low concentrations of hydrogen peroxide [75-80], in corresponding conditions to its concentration phase transition [3].

It is considered that hydrogen peroxide can be a signal molecule (non-contact action), transferring information from membrane receptors to related cytoplasmic effector or transcription factors [16]. Hydrogen peroxide 
is necessary for activation of the nucleic factor, which controls the synthesis of nitrogen oxide, one of the most powerful bactericidal factors of phagocytes [81]. According to work [82], reactive oxygen species, including peroxides, are part of the physiological route of signal transfer to the cell.

Considering the important role reactive oxygen species play in the regulation of cell metabolism, realized by way of macroscopic quantum interaction, as well as their dependence on the electron content in the environment, which is, in its turn, determined by variations of geomagnetic field of the Earth, connections between an organism's activity and the intensity of geomagnetic field become obvious. In this regard, daily variations of geomagnetic activity have a direct effect on the activity of cell mediators [72,83] and hormones [84,85].

Thus the intra-cellular processes are regulated via environment as a result of changes in structural changes in electrically active phase of water under the influence of low-intensity fields and radiation.

Theoretical aspects of environmental field factors influence on associated water phase electron crystal structure can be described using quantum approach to mesoscopic systems, but require additional application of mathematical apparatus of quantum electrodynamics and equations of fuzzy time fractional diffusion [8688] for the purpose of modeling water phase transition processes in a dynamically unstable quantum oscillator system of associated water phase.

Directed regulation and support of phase state structural stability, much needed for performing regulatory function in specific biological structures in the organism, is made possible with the use of membranotropic homeostatic tissue-specific bioregulators [89-90]. These bioregulators are large nanosized peptide-protein complexes and possess the ability to transmit their quantum state on associated water phase structures, which explains their maximum effectiveness in highly diluted water solutions $\left(10^{-2}-10^{-9} \mathrm{mkg} / \mathrm{l}\right)$. It's important to note, that a background of natural electromagnetic radiation is necessary for realizing the homeostatic function of these bioregulator solutions. Otherwise, (as shown during experimental screening of the solution from electromagnetic fields) there is no observable effect.

The homeostatic bioregulators presently undergoing clinical probing (series "Matrix»: «Salutem», «Decoris», «Cerebrum», «Visum» and others (more than 40 designations)) demonstrate ability to stimulate repair and regeneration processes in damaged and pathologically changed tissues, perform hepatoprotective function [91,92], are used in eye retina and eye nerve disorders («Matrix Visum») [93], in conductive sensorineural hearing loss therapy complex, for stabilizing arterial pressure («Matrix $\mathrm{P} 1$ и $\mathrm{P} 2 »$ preparations) and other disorders [94].

Therefore, quantum macroscopic states of electrons contained in ion-radical compound forms, including active oxygen forms, act as an inductor of cell processes. Therefore, varying in time effect on biological objects of amplitude and phase (magnetic vector potential) state regulation of macroscopic wave packets produced by electric charges of ion molecular compound forms in liquid, has regulating effect on temporary oscillations of potentialdependent protein structures (e.g., ketone and enol forms) produced in bound states of liquid. The system transforms into the macroscopic coherent state, which results in establishment of state correlations of bound phases of liquids defined by the conditions of interference of wave functions of wave electron packets.

Disruption and blockage of these primary regulation systems of cell metabolism, which occur when the ecological balance of electron component between the internal and external environments is disturbed, are to be viewed as the chief valeogenic factors determining the stability of body homeostasis. 


\section{REFERENCES}

Rakhmanin YA, Kondratov VK. Water as a space phenomenon: cooperative properties and biological activity. Moscow. RANS, RAMS. 427p. (2002).

Rakhmanin YA, Stekhin AA, Yakovleva GV. Structural-energetic changes of water and its biological activity. Gig. Sanit. 5, 34-36. (2007).

Stekhin AA, Yakovleva GV. Structured water: Non-linear effects. Moscow. LKI Publishing house. 325p. (2008).

Ling G. Physical theory of a living cell. Unnoticed revolution. Saint- Petersburg. Nauka, Publishing house. 374p. (2008).

Stekhin AA, Yakovleva GV. Methodological problems of study of electron state of environment-human system. Gig. Sanit. 5, 79-82. (2009).

Stekhin AA., Yakovleva GV. Regulation of quantum states of coherent nanoclusters of associated water. Gig. Sanit. 5, 23-26. (2008).

Elitzur AC, Dolev S. In The Nature of Time: Geometry, Physics and Perception. Bucceri R Kluwer (editor) Academic Publishers. 297. (2003).

Enshin AV, Iliodorov VA. Method of alteration of properties of paramagnetic gases. Application No.93050149. 03.11.93. Patent No.2094775 (Russia) (1997).

Enshin AV, Iliodorov VA. New quantum effects in the physics of macroworld. Report at Intern. Conf Science and future - ideas that will change the world. Moscow.

http://www.sciteclibrary.ru/rus/ catalog/pages/8036.html

Matveev AN. Mechanics and relativity theory: Textbook 3rd edn Moscow. Publishing House Oniks 21 vek, LLC. Publishing House "Mir i Obrazovanie", LLC, 432p. (2003).

Avramenko RF. The future is opened with a quantum key. (ed.) V.I.Nikolaeva, A.S.Pashina Moscow. Publishing house "Khimiya”. 352p. (2000).

Avramenko RF, Nikolaeva VI. Quantum energy of electron Bose condensate in the environment. Moscow. Publishing house "Khimiya”. 32p. (1991)

Giudice DE, Milani M, Mengo G, et al. Coherent Quantum Electrodynamics in Living Matter. Electromagn. Biol. Med. 24(3), 199-210 (2005).

Frolich H. Long-range Coherence and Energy Storage in Biological Systems. Int. J. Quantum Chem. 2(5), 641-649. (1968).

Shmidt VV. Introduction to physics of superconductors. 2nd edition, revised and amended. Moscow. Publishing house “MCNMO”. 402p. (2000).

Gulian AM, Zharkov GF. Superconductors in external fields (unbalanced phenomena). Moscow. Publishing house "Nauka". 296p. (1990).

Arai T, Endo N, Yfmfshita K, et al. 6-formylpterin, a xanthine oxidase inhibitor, intracellularly generates reactive oxygen species involved in apoptosis and cell proliferation. Free Radic. Biol. Med. 30(3), 248-259 (2001).

Klotz LO. Oxidant-induced signaling: Effects of peroxynitrite and singlet oxygen. Biol. Chem. 383(3-4), 443-456 (2002).

Kunsch C, Medford RM. Oxidative Stress as a Regulator of Gene Expression in the Vasculature. Circ. Res. 85(5), 753766 (1999).

Liou JS, Chen CY, Chen JS, et al. Oncogenic ras-mediates apoptosis in response to protein kinase $\mathrm{C}$ inhibition through the generation of reactive oxygen species. J. Bio. Chem. 275(50), 3900139011 (2000)

Meister A. Glutatione, ascorbate, and cellular protection. Cancer Res. 54(7), 1969-1975 (1994).

Oberley TD, Schultz JL, Oberley LW. Antioxidant enzyme levels as a function of growth state in cell culture. Free Radic. Biol. Med. 19(1), 53-65 (1995).

Bogachev YS. Spectral-structural objective laws of formation of hydrogen bonds in concentrated aqueous and organic systems. Synopsis of thesis of $\mathrm{PhD}$ (Chem.) Moscow. NIFHI. 46p. (1992).

Giudice DE, Tedescki A. Water and
Autocatalysis in Living Water. Electromagn. Biol. Med. 28(1), 46-52 (2009).

Imri J, Webb RV. World of science. 6, 24-31 (1989).

Gamaley IA, Klybin IV. Roles of reactive oxygen species: signaling and regulation of cellular functions. Int. Rev. Cytol. 188, 203-255 (1999).

Krieger-Brauer HI, Kather $\mathrm{H}$. The stimulus-sensitive $\quad \mathrm{H}_{2} \mathrm{O}_{2}$-generating system present in human fat-cell plasma membranes is multireceptor-linked and under antagonistic control by hormones and cytokines. Biochem. J. 307(Pt 2), 543548 (1995).

Gennis R. Biomembranes: molecular structure and functions. Moscow. Publishing House "Mir" 624p. (1997).

Koldunov VV, Kononov DS, Voeikov VL. In: Biophotonics and Coherent Systems. Proceedings of the 2nd International Alexander Gurwitsch Conference and Additional Contributions.

Beloussov L, Popp FA, Voeikov V, Van Wijk R (editors). Publishing House Moscow University Press: Moscow. 229240 (2000).

Voeykov VL, Koldunov VV, Kononov DS. Long oscillations of chemoluminescence in course of amincarbonile reaction in aqueous solutions. $J$. Phys. Chem. 75, 1579-1585 (2001).

Marrey R, Grenner D, Meyers P, et al. Human biochemistry. Vol. 1-2. Moscow (1993).

Kotelnikov AI. Proteins as natural nanostructures. Role of quantum and dynamic factors in distant transfer of electron in proteins. Russian Chem. magazine (Mag. of D.I. Mendeleev Russian Chemical Society). XLVI(5) (2002).

Moller IM. Plant Mitochondria and Oxidative Stress. Electron Transport, NADH Turnover and Metabolism of Reactive Oxygen Species. Annu. Rev. Plant Physiol. Plant Mol. Biol. 52, 561-591 (2001).

Murphy MH. How Mitochondria Produce Reactive Oxygen Species. Biochem. J. 417(1), 1-13 (2009). 
Kuznetsov VD, Mishinsky GV, Penkov FM, et al. Low Energy Transmutation of Atomic Nuclei of Chemical Elements. Annales de la Foundation Louis de Broglie. 28(2), 173- 214 (2003).

Gamaley IA, Kliubin IV. Hydrogen peroxide as signaling molecule. Cytol. 38(12), 1233-1247 (1996).

Shutov AM, Saenko AM. Role of oxidative stress in pathology of cardiovascular system in patients with kidney disease. Nephrol. Dialysis. 1, 47-53 (2004).

Manna SK, Zhang HJ, Yan T. Overexpression of manganese superoxide dismutase suppresses tumor necrosis factor-induced apoptosis and activation of nuclear transcription factor-kappa $\beta$ and activated protein. J. Biol. Chem. 273(21), 13245-13254 (1998).

Pastore D, Trono D, Laus MN, et al. Possible Plant Mitochondria Involvement in Cell Adaptation to Drought Stress. J. Exp. Bot. 58(2), 195-210 (2007).

Prasad TK, Anderson MD, Stewart CR. Localization and Characterization of Peroxidases in the Mitochondria of Chilling-Acclimated Maize Seedlings. Plant Physiol. 108(4), 1597-1605 (1995).

Jimenez A, Hernandez JA, Pastori G, et al. Role of Ascorbate-Glutathione Cycle in Mitochondria and Peroxisomes in the Senescence of Pea Leaves. Plant Physiol. 118(4), 1327-1335 (1998).

Navrot N, Rouhier N, Gelhaye E, et al. Reactive Oxygen Species Generation and Antioxidant Systems in Plant Mitochondria. Physiol. Plant. 129(1), 185-195 (2007).

Sweetlove LJ, Heazlewood JL, Herald $\mathrm{V}$, et al. The Impact of Oxidative Stress on Arabidopsis Mitochondria. Plant J. 32(6), 891-904 (2001).

Salvi M, Battaglia V, Brunati AM, et al. Catalase Takes Part in Rat Liver Mitochondria Oxidative Stress Defense. J. Biol. Chem. 282(33), 24407-24415. (2007).

Moreno-Loshuertos R, Acín-Pérez R, Fernández-Silva P, et al. Differences in reactive oxygen species production the explain phenotypes associated with common mouse mitochondrial DNA variants. Nature Genetics. 38(11), 12611268 (2006).

Baughman JM, Mootha VK. Buffering mitochondrial DNA variation. Nature Genetics. 38(11), 1232-1233 (2006).

Keilhack H, Muller M, Bohmer SA, et al. Negative regulation of ROS receptor tyrosine kinase signaling. An epithelial function of the $\mathrm{CH}_{2}$ domain protein tyrosine phosphatase SHP-1. J. Cell. Biol. 152(2), 325-334 (2001).

Gudrinietse EY (editor). Structure and tautomeric transformations of $\beta$-dicarbonyl compounds. Riga (1977).

Chernykh AM, Boriseyko AN, Kovalchuk ML. Shielding of geomagnetic field in residential buildings. Gig. Sanit. 5, 69-71 (2009).

Irani K. Oxidant signaling in vascular cell growth, death, and survival. Circ. Res. 87(4), 179-183 (2000).

Filnkel T. Redox-dependent signal transduction. FEBS Lett. 476(1-2), 52-54 (2000).

Jing X, Ueki N, Cheng J, et al. Induction of apoptosis in hepatocellular carcinoma cell lines bv emodin. Jap. J. Cancer Res. 93(8), 874-882 (2002).

McGeehin MA, Mirabelli M. The potential impacts of climate variability and change on temperature-related morbidity and mortality in the United States. Environmental Health Perspectives. 109(2), 185-189 (2001).

Fafelov AK. Regulation of meteorological processes by electromagnetic method. Results of activity of the group "Noosphere knowledge and technologies' (June 1995 - October 2005) Moscow. 216-221. (2005).

Everi G. Basics of kinetics and mechanisms of chemical reactions. Publishing house Mir: Moscow. 214p. (1978).

Bauer G, Saran M, Herdener M, et al. Target cell derived superoxide anions cause efficiency and selectivity of intercellular induction of apoptosis. Free Radic. Biol. Med. 29(12), 1260-1271 (2000).
Fridrich P. Enzymes: Quaternary structure and supermolecular complexes. Publishing house Mir: Moscow. 202p. (1986).

Zefirov NS (editor). Chemical Encyclopedia, vol.2, 3 Publishing house Great Russian Encyclopedia: Moscow. (1999).

Davis WJr, Ronai Z, Tew KD. Cellular thiols and reactive oxygen species in drug induced apoptosis. J. Pharmacol. Exp. Ther. 296(1), 1-6 (2001).

Ben Mahdi MH, Andrieu V, Pasquier C. Focal adhesion kinase regulation by oxidative stress in different cell types. Life. 50(4-5), 291-299 (2000).

Hoigne J, Zuo Y, Nowell L. Photochemical reactions in atmospheric waters; role of dissolved iron species. Aquatic Surface Photochem. (1999).

Mates J, Perez-Gomez C, Nunez de Castro I. Antioxidant enzymes and human diseases. Clin. Biochem. 32(8), 595-603 (1999).

May JM. Is ascorbic acid an antioxidant for the plasma membrane? FASEB J. 13(9), 995-1006 (1999).

Napoli C, de Nigris E, Palinski W. Multiple role of reactive oxygen species in the arterial wall. J. Cell. Biochem. 82(4), 674-682 (2001).

Qi X, Chen Y, Wang Z, et al. The role of superoxide anion in the regulation of epidermal growth factor or the expression and proliferation of its receptor in PROC cell line PC3. Urol. Res. 30(1), 48-52 (2002).

Chiarugi P. Reactive oxygen species as mediators of cell adhesion. Ital. J. Biochem. 52(1), 28-32 (2003).

Chiarugi P. The redox regulation of LMW-PTP during cell proliferation or growth Inhibition. IUBMB Life. 52(1-2), 55-59 (2001).

Bay IL, Sit KH, Paramanantham R, et al. Hydroxyl free radicals generated by vanadyl [IV] induce cell blebbing in mitotic human change liver cells. Biometals 10(2), 119-122 (1997).

Fiaschi T, Chiarugi P, Buricchi E 
et al. Low molecular weight proteintyrosine phosphatase is involved in growth inhibition during cell differentiation. J. Biol. Chem. 276(52), 49156-49163 (2001).

Zhang TC, Schmitt MT, Mumford JL. Effects of arsenic on telomerase and telomeres in relation to cell proliferation and apoptosis in human keratinocytes and leukemia cells in vitro. Carcinogenesis. 14(2), 342-354 (2003).

Esposito E, Chirico G, Gesualdi NM, et al. Protein kinase B activation by reactive oxygen species is independent of tyrosine kinase receptor phosphorylation and requires SRC activity. J. Biol. Chem. 278(23), 20828-20834 (2003).

Tikoo K, Lau SS, Monks TJ. Histone H3 phosphorylation is coupled to poly(ADP-ribosylation) during reactive oxygen species-induced cell death in renal proximal tubular epithelial cells. Mol. Pharmacol. 60(2), 394-402 (2001).

Gamaley IA, Klcubin IV. Roles of reactive oxygen species: signaling and regulation of cellular functions. Int. Rev. Cytol. 188(1), 203-255 (1999).

Chen Z, Silva H, Klessig DF. Active Oxygen Species in the Induction of Plant Systemic Acquired Resistance by Salicylic Acid. Science. 262(5141), 1883-1886 (1993).

Desikan R, Mackerness SA, Hancock JT, et al. Regulation of the Arabidopsis Transcriptome by Oxidative Stress. Plant Physiol. 127(1), 159-172 (2001).

Desikan R, Hancock JT, Neill SJ. Oxidative Stress Signaling. Plant Responses to Abiotic Stress: Topic in Current Genetics. Verlag. 121-148 (2003).
Mori IC, Schroeder JI. Reactive Oxygen Species Activation of Plant Ca2 ${ }^{+}$ Channels: A Signaling Mechanism in Polar Growth, Hormone Transduction, Stress Signaling, and Hypothetically Mechanotransduction. Plant Physiol. 135(2) 702-708 (2004).

Foyer CH, Noctor G. Redox Homeostasis and Antioxidant Signaling: A Metabolic Interface between Stress Perception and Physiological Responses. Plant Cell. 17(7), 1866-1875 (2005).

Galvez-Valdivieso G, Mullineaux PM. The Role of Reactive Oxygen Species in Signalling from Chloroplasts to the Nucleus. Physiol. Plant. 138(4), 430-439 (2010).

Schulze-Osthoff K, Los M, Bauerle PA. Redox signaling by transcription factors NF-kb and AP-I in Lymphocytes. Biochem. Pharmacol. 50(6), 735-741 (1995).

Skulachev VP. Energy of biological membranes. Moscow. Publishing house "Nauka”. 564p. (1989).

Gavrilov OK. Biological laws of regulation of blood condition and aims of its study. Issues Hematol. Blood Transfusion. 7(4), 2-8 (1979).

Thannickal VJ, Fanburg BL. Reactive oxygen species in cell signaling. Am. J. Physiol. Lung. Cell. Mol. Physiol. 279(6), L1005-L1028 (2000).

Moskalets MV. Foundations of mesoscopic physics. Kharkov: NTU "KPI". 2010.

Arqub OA, AL-Smadi M, Momani $S$, Hayat T. Numerical solutions of fuzzy differential equations using reproducing kernel Hilbert space method. Soft Comput.
20(8), 3283-3302 (2016).

Arqub OA, AL-Smadi M, Momani $S$, Hayat T. Application of reproducing kernel algorithm for solving second-order, two-point fuzzy boundary value problems. Soft Comput. 21(23), 7191-7206 (2017).

Arqub OA, AL-Smadi M, Momani S, Hayat T. Adaptation of reproducing kernel algorithm for solving fuzzy FredholmVolterra integrodifferential equations. Neural Comput. App. 28(7), 1591-1610 (2017).

Yamskova VP, Krasnov MS, Yamskov IA. Novel experimental and theoretical aspects in bioregulation. Membranotropic homeostatic tissue-specific bioregulator function mechanism. Lambert. 136 (2012).

Jahed Z, Shams H, Mehrbod M, Mofrad MR. Mechanotransduction pathways linking the extracellular matrix to the nucleus. Int. Rev. Cell Mol. Biol. 310(1), 171-220 (2014).

Ryzhkina IS, Murtazina LI, Konovalov AI. External electromagnetic field effect a necessary condition for nanoassociate formation in highly diluted water solutions. Academy Sci. 440(6), 778-781 (2011).

Nalobin DS. The effect of bioregulators isolated from mammal liver and blood serum for regenrative replacement of rat liver. Dissertation. Moscow. 2016.

Konstantinosky AA, Krasnov MS, Yamskova VP, et al. Research of wound healing effect of bioregulators, isolated from ox eye tissues and blood serum in experimental model using rabbit cornea in vivo. Bulletin of Experimental Biology and Medicine. 153(2), 177-182 (2012). 